\begin{tabular}{|l|l|}
\hline $\begin{array}{l}\text { Postprint } \\
\text { Version }\end{array}$ & 1.0 \\
\hline $\begin{array}{l}\text { Journal website } \\
\text { Pubmed link }\end{array}$ & $\begin{array}{l}\underline{\text { http://search.ebscohost.com/login.aspx?direct=true\&db=afh\&AN=9604261369\&si }} \\
\underline{\underline{\text { he=ehost-live }}}\end{array}$ \\
\hline DOI & \\
\hline
\end{tabular}

This is a NIVEL certified Post Print, more info at http://www.nivel.eu

\title{
PRIMARY HEALTH CARE PHYSICIANS' TREATMENT OF PSYCHOSOCIAL PROBLEMS: Implications for Social Work.
}

\author{
Gross, ReVital, RABinOWitZ, JonATHAN, FELDMAN, Dina, BoERMAN, WienKE
}

This study explores the extent to which primary care physicians serve as gatekeepers for the treatment of psychosocial problems and the extent to which they have contact with social workers. We also attempted to identify physician variables related to gatekeeping and amount of contact with social workers. Data from a national study of the role of primary care physicians in Israel were used. About one-third of the physicians had regular contact with social workers, onequarter had contact less often, and about one third almost never had contact. Variables associated with gatekeeping for psychosocial problems included having a large caseload, specializing in family medicine, practicing in a rural location, and being under age 55 . Variables associated with social work contact were affiliation with the largest health maintenance organization and specialization in family medicine.

Many visits to primary health care physicians are related to psychosocial problems. Physicians often treat these problems themselves and rarely refer patients to mental health professionals (J ones, Badger, Ficken, Leeper, \&Anderson, 1987; Regier et al., 1993; Schurman, Kramer, \& Mitchell, 1985; Zimmerman \& Wienckowski, 1991). Some have called primary health care physicians the "de facto mental health care system" [italics added] Regier et al., 1993, p. 85). In social services and mental health settings, social workers are most frequently the ones who care for psychosocial problems. In the United States, the locus of care for many psychosocial problems can be expected to shift to primary health care settings as health care reform moves toward integrating mental health into the general health care system. Such a system, as has recently been outlined by Mechanic (1994), will increase the likelihood that people will receive the most appropriate form of care. In such an integrated system, the primary health care physician would serve as a gatekeeper for other, nonmedical services. Even now, the move toward managed care and care centered around health maintenance organizations (HMOs) presents social workers with opportunities and challenges.

The literature suggests that primary health care physicians need the special knowledge and skills that social workers and other mental health professionals can contribute. Despite the substantial role that primary health care physicians play in treating psychosocial disorders, there is evidence that they often fail to identify and treat mental health problems in general (Sartorius et al., 1993) and substance abuse in particular (Milhorn, 1988). Social work intervention could be an asset in primary care settings; moreover, it has been shown that interventions reduce the utilization of medical care (Jones \& Vischi, 1979; Kiesler, Cummings, \& VandenBos, 1979; Mumford, Schlesinger, \& Glass, 1982; Schlesinger, Mumford, Glass, Patrick, \& Sharfstein, 1983). Social workers could help physicians by teaching them psychosocial skills (Zayas \& Dyche, 1992). 
Yet, to date, social workers have struggled to define their role in the primary health care setting (Greene, Kruse, \& Arthurs, 1985; Gross \& Gross, 1987b; Gross, Gross, \& Eisenstein-Naveh, 1983) owing to inherent strain between the professions due to differences in values relating to patient care, such as saving life versus quality of life, and differing views on patient autonomy and the role of the health care professional (Abramson \& Mizrahi, 1986; Mizrahi \& Abramson, 1985; Roberts, 1989). The work done on social worker and primary care physician collaborations suggests that younger physicians have more positive attitudes toward social work interventions (Gross \& Gross, 1987a). In view of the changes in the health care system and the vital need for social workers in an integrated system of health care, social workers should consider their role in primary health care settings and vis-a-vis primary health care physicians.

This article discusses the extent to which primary care physicians act as gatekeepers for psychosocial problems and the extent of their contact with social workers. Given that almost all health care in Israel is provided by HMOs, the situation in Israel, where this study was conducted, may be instructive for professionals in the United States and other countries, where health care is increasingly being based on HMOs. In Israel most health care is provided by one large HMO run by the national labor union and heavily subsidized by the government. The predominance of care is provided by salaried physicians. In the smaller HMOs the predominance of care is provided by independent physician practitioners. Most social workers are employees of the HMOs. Their primary role is to deal with patients who present psychosocial problems. Although patients can seek out social work assistance, patients are typically referred to social workers after reaching an impasse with the health care system. Social workers give direct treatment services and also refer patients to other services.

\section{RESEARCH QUESTIONS}

We explored the following questions about the role of primary care physicians in treating psychosocial problems: To what extent, and for which psychosocial problems, do primary care physicians serve as gatekeepers? What characterizes those physicians who are the most active as gatekeepers for psychosocial problems? How much contact do these physicians have with social workers? What characterizes those physicians who have most frequent contact with social workers? How are the two measures of involvement with psychosocial problems -- gatekeeping and contact with social workers -- related?

\section{METHOD}

Data were taken from a national study on the role of primary care physicians in Israel. The physicians were asked to respond to the Task Profiles of General Practitioners in Europe questionnaire (Boerma, 1993) as part of a multinational study of primary care physicians in 30 European countries. Respondents completed and mailed in the self-administered questionnaire, which included questions about their contact with social workers; their encounters with psychosocial problems; and their backgrounds, practice settings, caseloads, medical activities, and other subjects related to their work.

The study used a stratified random sample of 1,065 primary care physicians drawn from a national list of 2,925 such physicians One hundred and ninety-three physicians were removed from the sample because they were no longer practicing primary medicine. Of the remaining 872 physicians, 677 ( 77.6 percent) responded. The high response rate is probably due to telephone follow-up. The most common reasons for nonresponse were refusal, return of the questionnaire by the physician but nonreceipt by the researchers, and inability to locate the physician. The rate of nonresponse to individual items ranged from 0 percent to 28 percent. There were no significant differences in response rate according to gender or $\mathrm{HMO}$ affiliation. The response rate was higher for specialists in family medicine (80 percent, $n=334$ ) than for general practitioners ( 72 percent, $n=343$ ) and higher for salaried physicians (80 percent, $n=430$ ) than for independent practitioners (71 percent, $n=127$ ). As a result, there was a higher percentage of specialists in family medicine among the respondents (49 percent, $n=334$ ) than among the nonrespondents ( 30 percent, $n=59$ ) and a lower percentage of independent practitioners among the respondents ( 19 percent, $n=127$ ) than among the nonrespondents ( 27 percent, $n=$ 53). The results were weighted by strata to compensate for nonrespondents. 
Data were analyzed using descriptive statistics and cross-tabulations to explore frequencies and relationships among variables. Because multiple comparisons were used, we set acceptable probability levels at $p<.005$ (Grove \& Andreasen, 1982). The independent effects of each predictor variable were explored using logistic regression, which is a form of multiple regression designed for dichotomous dependent variables. Using logistic regression we were able to estimate the increase in probability of gatekeeping for psychosocial problems and having contact with social workers for each significant independent variable. (For a more detailed description of how this was done, see Norusis, 1990.) The independent variables were gender, age (over or under age 55), size of caseload (more or fewer than 1,000 patients), location (rural or urban), salaried or independent, specialist in family medicine (hereafter referred to as family physician) or general practitioner, and affiliation with Israel's largest HMO or with one of the smaller HMOs.

\section{RESULTS ROLE OF GATEKEEPER}

The researchers asked seven questions concerning how often the physicians were the first contact for patients with each of seven common psychosocial problems (Table 1). Responses were on a four-point scale ( 1 = always, $2=$ usually, $3=$ occasionally, and $4=$ never) that was aggregated into two groups: usually/always and occasionally/never. The primary care physicians were frequently gatekeepers for typical psychosocial problems but less often were gatekeepers for problems such as child abuse. For example, it is interesting to note that 70 percent $(n=453)$ of the 647 primary care physicians who responded to the question said they were the first contact for women with psychosocial problems related to work. This may be of special interest to social workers, who typically treat such problems.

To see if physicians who were gatekeepers for one type of problem were gatekeepers for others as well, we checked the internal consistency of answers to these seven questions and found it high (Cronbach's alpha $=.86$ ). We therefore aggregated the answers into a single measure showing the number of psychosocial problems for which primary care physicians served as gatekeepers. For each problem we defined the categories always, usually, and occasionally as "has first contact," assigning a value of 1 , and the category never as "does not have first contact," assigning a value of 0 . We then counted the number of values of 1 , which ranged from 0 to 7 . We found that about 39 percent $(n=262)$ of the physicians reported haying first contact with all seven problems, 37 percent $(n=251)$ reported having first contact with four to six problems, 18 percent $(n=123)$ reported having first contact with one to three problems, and only 6 percent $(n=41)$ reported not having first contact with any of the psychosocial problems.

Next we explored which physician characteristics were associated with having first contact with all seven psychosocial problems. The physicians who had first contact with all seven problems tended to be under age 55 [ 44 percent $(n=219)$ versus 24 percent $(n=43)$ of those over age 55 ; $X[\sup 2](1, N=675)=24.4, p=.000]$; family physicians rather than general practitioners [55 percent $(n=119)$ versus 31 percent $(n=139) ; X[\operatorname{sup2}](1, N=667)=37.6, p=.000]$; practicing in rural rather than urban areas [49 percent $(n=130)$ versus 32 percent $(n=126)$; $X[\sup 2](1, N=658)=17.5, p=.000]$; and carrying a caseload of more than 1,000 patients [46 percent $(n=209)$ versus 20 percent $(n=36)$ of those with caseloads of fewer than 1,000 patients; $X[\sup 2](1, \mathrm{~N}=626)=35.5, \mathrm{p}=.000]$.

To study the independent effect and estimate the influence of each variable, a logistic regression model was constructed (see Table 2). Based on this model, the probability of a physician having contact with all seven psychosocial problems increases from 11 percent for physicians who are over age 55, are general practitioners, and have a smaller caseload and an urban practice to 70 percent for physicians who are under age 55, are family physicians, and have a larger caseload and a rural practice.

\section{CONTACT WITH SOCIAL WORKERS}

Thirty percent ( $n=191$ ) of the physicians reported having contact with social workers more than once a month. Twenty-four percent $(n=152)$ reported having such contact every one to three months, 15 percent $(n=96)$ reported having contact with social workers less than three times a 
Gross, R., Rabinowitz, J., Feldman, D., Boerma, W. Primary health care physicians' treatment of psychosocial problems: implications for social work. Health \& Social Work: 1996, 21(2), 89-95

year, 20 percent ( $n=130$ ) reported having such contact seldom or never, and the remaining 11 percent $(n=67)$ responded that the question was not relevant to them.

To identify physician variables related to social work contact, we divided the physicians into two groups: those who met with social workers more than once a month and those who did not. We found more frequent contact with social workers among family physicians than among general practitioners [47 percent $(n=89)$ versus 27 percent $(n=102) ; X[\operatorname{sup2}](1, N=574)=18.5, p<$ .000]; among physicians affiliated with the largest HMO, most of whom were salaried and worked in clinics, than among other physicians [42 percent $(n=166)$ versus 13 percent $(n=23)$; $X[\sup 2](1, N=571)=13.7, p<.000]$; and among physicians who were salaried than among those who were independent practitioners [38 percent $(n=172)$ versus 16 percent $(n=19)$; $X[\sup 2](1, \mathrm{~N}=641)=19.15, \mathrm{p}<.00001]$.

Table 3 presents a logistic regression model predicting contact with social workers more than once a month. This model shows that two of the four variables identified in the univariate analysis each have an independent effect on frequent contact with social workers; it also approximates the influence of each variable. Based on this model, the probability of a physician having frequent contact with a social worker increases from 12 percent for general practitioners and physicians who are not affiliated with the largest HMO to 50 percent for family physicians and physicians who are affiliated with the largest HMO.

\section{RELATIONSHIP BETWEEN GATEKEEPING AND CONTACT WITH SOCIAL WORKERS}

Significantly more of the physicians who had first contact with all seven psychosocial problems than those who did not also had frequent contact with social workers [36 percent $(n=94)$ versus 23 percent $(n=97)$; $X[\sup 2](1, N=575)=6.65, p=.01]$. We used two logistic regression models to attempt to determine whether the relationship between these two variables was independent of the effects of the other related variables. In one model we attempted to predict contact with social workers by including the significant independent variables from the previous logistic regression (see Table 3) and physician gatekeeping. We next constructed a model using physician gatekeeping as the dependent variable and contact with social workers and the other significant variables as independent variables. In both models the relationship between gatekeeping and contact with social workers was not significant, suggesting that these two variables are independent of one another. The results of these models are represented in Table 4 , which shows the estimated contribution in probability added by each variable. For example, being a family physician increases the probability of gatekeeping for psychosocial problems by 22 percent and increases the probability of frequent contact with social workers by 14 percent. As can be seen, being a family physician is the only variable common to both models.

\section{DISCUSSION}

The results show that physicians serve an important role as gatekeepers for an array of psychosocial problems. They are usually or always the first contact for as many as 85 percent and no less than 44 percent of typical psychosocial problems. Because this study inquired about first contacts only, we do not know what happened thereafter--that is, whether the physicians continued to treat these patients or referred them elsewhere. About 30 percent of the physicians reported having regular contact with social workers, about one quarter reported having contact less often, and about one-third reported almost never having contact with social workers. The one variable that increased the probability of both gatekeeping and social work contact was specialization in family medicine. We suspect that family physicians are more involved in treating psychosocial problems because they are trained to do so.

Although the study drew on a very carefully selected probability sample, the data collected were from self-reports; physicians may have overreported because they thought treating psychosocial problems to be considered desirable. The physicians' responses to the entire Netherlands Institute of Primary Health Care (NIVEL) questionnaire were checked for validity and reliability against other comparable data sources and were found to be generally reliable (Gross, Yuval, Japhe, \& Boerma, 1994). Doubt could be raised regarding the physicians' knowledge of how often they actually were a patient's first contact with the health system, given that they could not 
know whether a patient had gone elsewhere. To allay --his doubt, we dichotomized their answers--"has first contact" and"does not have first contact"--based on the plausible assumption that physicians could know whether they had or had not encountered psychosocial problems. In a future study, patient responses to this question can be elicited and compared with those of the physicians. Another limitation of the study is that the questionnaire did not include questions about the nature of cooperation between primary care physicians and social workers (for example, referral, consultation, joint treatment, and so forth); further research should be conducted to fully understand this issue. Other areas for future research are physicians' involvement with a broader array of psychosocial problems and their referral patterns when given a choice among social workers and allied professionals.

It could be expected that physicians who are in more frequent contact with social workers learn from them and become sensitized to screening for psychosocial problems, as was found in the bivariate analysis. However, the findings from the logistic regression suggest that frequent contact with social workers does not have an independent effect on gatekeeping for psychosocial problems. A possible explanation might be that a third variable, training in family medicine, has a dominant effect on both of these variables and has created a spurious relationship in the bivariate analysis. Maybe the pattern of relationship with social workers is established early in the training of physicians (at medical school) and cannot be easily changed. As suggested by others (Greene et al., 1985), social workers should be assertive in marketing their services and not rely on regular day-to-day contacts with physicians as a means for changing physicians' altitudes.

Despite these limitations, the findings have important implications for social work practice. On one hand, if primary care physicians take the role of gatekeeper for psychosocial problems, social workers may feel their role has been usurped. On the other hand, the findings suggest that primary care physicians, particularly specialists in family medicine, are, as has been suggested by Roberts (1989), natural partners for social workers. Yet to date, the extent of this partnership has been limited. As HMOs, managed care, and integrated models of mental and general health care proliferate and cost containment and utilization controls become imperative, physicians may increasingly become gatekeepers for most social work services. Moreover, there is likely to be less and less direct access to social workers in primary care settings. It is therefore important for social workers to strengthen their alliances with primary health care physicians.

It is also essential that social workers become assertive in marketing their services to primary care physicians. Given that physicians currently control the point of entry into primary health care clinics and that this is not likely to change, social workers should focus on specific means of enhancing their collaboration with physicians and of developing social work as a distinctly defined part of primary care. For example, social workers could disseminate a document precisely defining their professional activities and describing the contribution of social work to the care of common psychosocial problems. In fact, some have already done this (Gross et al., 1983). Social workers could also conduct a planned public relations campaign targeted at young family physicians with large patient lists who practice in rural areas, because these physicians encounter psychosocial problems more often than do other physicians. Finally, it would be advisable for social workers to initiate regular meetings with primary care physicians, thereby creating a forum for discussion of joint treatment, fostering a collaborative atmosphere, and coordinating work patterns for the future.

Collaboration should be possible because it is in the best interest of all those involved--physicians, social workers, and HMOs. In most settings, primary care physicians do not have the time--or, probably, the expertise--to treat many psychosocial problems. Medical organizations might well encourage such collaboration for financial reasons: Physician services are more costly than are social work services. Furthermore, successful psychosocial intervention can lower unnecessary use of medical services. Finally, to strengthen the status of social work as a profession, social workers themselves have an interest in taking the initiative and forging an expanded role for them selves in primary health care settings.

Table 1. Percentage of Physicians who Act as

Gatekeepers for Psychosocial Problems 
Gross, R., Rabinowitz, J., Feldman, D., Boerma, W. Primary health care physicians' treatment of psychosocial problems: implications for social work. Health \& Social Work: 1996, 21(2), 89-95

Problem Presented

Physician Has

in the Questionnaire

First Contact

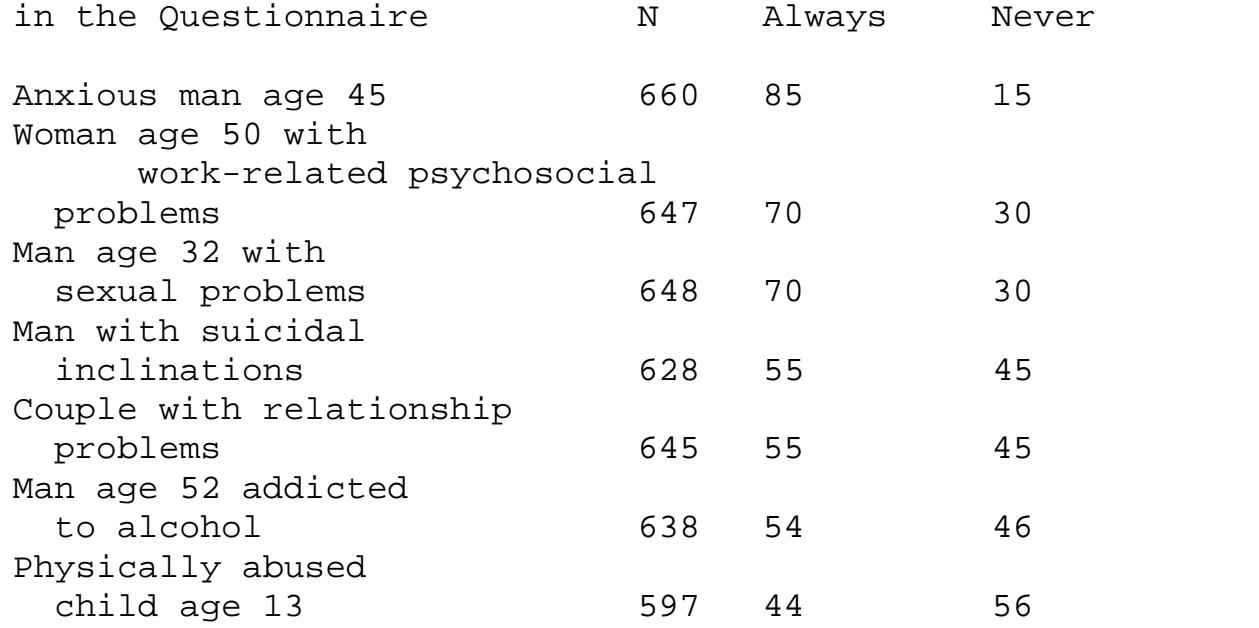

Table 2. Characteristics of Physicians Who Do Extensive Gatekeeping for Psychosocial Problems, Using a Stepwise Logistic Regression

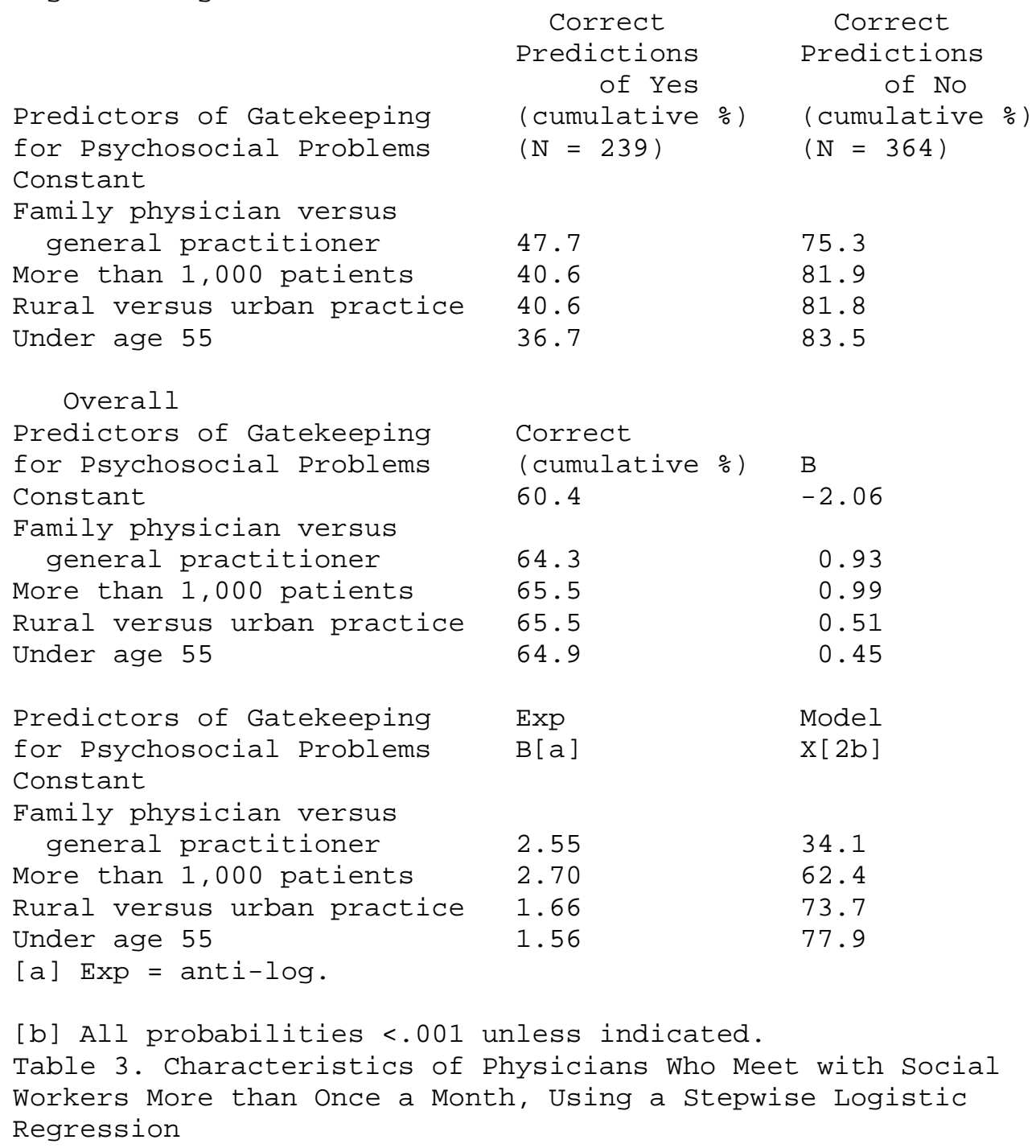


Predictors of

Frequent Contact

with Social Workers

Constant

Employed by largest HMO versus other HMO

Family physician versus general practitioner

Predictors of

Frequent Contact

with Social Workers

Constant

Employed by largest HMO versus other HMO

Family physician versus general practitioner

Predictors of

Frequent Contact

with Social Workers

Constant

Employed by largest HMO versus other HMO

Family physician versus general practitioner

Note: $\mathrm{HMO}=$ health maintenance organization.

$\odot .0 \odot$

43.29

Overall

Correct

66.9

66.9

66.9

Exp

$B[a]$

1.81
Correct

Predictions of

Frequent Contact (cumulative \%)

$(\mathrm{N}=189)$

Correct

Predictions of

Infrequent Contact

(cumulatiev \%)

$(N=382)$

100.00

(cumulative \%) B

$-2.00$

1.41

.60

Model

$X[2 \mathrm{~b}]$

$4.10 \quad 48.0$

57.6

Table 4. Variables Increasing the Probability

of Physician Gatekeeping and Social Worker

Contact, Based on Logistic Regression

(Percentage)

$$
\text { Gatekeeping Social Worker }
$$

$\begin{array}{lll}\text { Variable } & & \text { Contact } \\ \text { Large caseload } & 23 & -- \\ \text { Rural practice } & 11 & -- \\ \text { Under age 55 } & 10 & -- \\ \text { Family physician } & 22 & 14 \\ \text { Affiliated with } & & \\ \quad \text { largest HMO } & -- & 31\end{array}$

Notes: -- = data not applicable. $\mathrm{HMO}=$ health maintenance organization.

\section{REFERENCES}

Abramson, J ., \& Mizrahi, T. (1986). Strategies for enhancing collaboration between social workers and physicians. Social Work and Health Care, 12, 1-21.

Boerma, W. (1993). Task Profiles of General Practitioners in Europe [Questionnaire]. Utrecht: Netherlands Institute of Primary Health Care.

Greene, G., Kruse, K A., \& Arthurs, R J. (1985). Family practice social work: A new area of specialization. Social Work and Health Care, 10, 53-73.

Gross, A. M., \& Gross, J. (1987a). Attitudes of physicians and nurses towards the role of social workers in primary health care: What promotes collaboration? Family Practice, 4, 266-270. 
Gross, R., Rabinowitz, J., Feldman, D., Boerma, W. Primary health care physicians' treatment of psychosocial problems: implications for social work. Health \& Social Work: 1996, 21(2), 89-95

Gross, A. M., \& Gross, J. (1987b). Reducing physician and social worker conflict--The use of time and task analysis. Asia Pacific J ournal of Public Health, 1, 55-61.

Gross, A. M., Gross, J., \& Eisenstein-Naveh, A. R. (1983). Defining the role of the social worker in primary health care. Health \& Social Work, 8, 174-181.

Gross, R, Yuval, D., Japhe, Y., \& Boerma, W. (1994). The role of the primary care physician in Israel: Preliminary findings from a national survey. Jerusalem: JDC--Brookdale Institute of Gerontology and Human Development.

Grove, W. M., \& Andreasen, N. C. (1982). Simultaneous tests of many hypotheses in exploratory research. J ournal of Nervous and Mental Disease, 170, 3-8.

J ones, D., \& Vischi, T. (1979). I mpact of alcohol, drug abuse, and mental health treatment on medical care utilization. Medical Care, 17, 1-82.

J ones, L R., Badger, L. W., Ficken, R. R, Leeper, J. D., \& Anderson, R. L. (1987). Inside the hidden mental health network: Examining mental health care delivery of primary care physicians. General Hospital Psychiatry, 9, 287-293.

Kiesler, C. A., Cummings, N. A., \& VandenBos, G. R (1979). Psychology and national health insurance. Washington, DC: American Psychological Association.

Mechanic, D. (1994). Integrating mental health into a general health care system. Hospital and Community Psychiatry, 45, 893-897.

Milhorn, H.T.J. (1988). The diagnosis of alcoholism. American Family Physician, 37,175-183.

Mizrahi, T., \& Abramson, J. (1985). Sources of strain between physicians and social workers: Implications for social workers in health care settings. Social Work and Health Care, 10, 33-51.

Mumford, E., Schlesinger, J. J., \& Glass, G. V. (1982). The effects of psychological intervention on recovery from surgery and heart attack: An analysis of the literature. American J ournal of Public Health, 72, 141-151.

Norusis, M. J. (1990). Logistic regression analysis: Procedure LOGISTIC REGRESSION. In SPSS/PC+ advanced statistics 4.0 (pp. B39-B61). Chicago: SPSS.

Regier, D. A., Narrow, W. E., Rae, D. S., Manderscheid, R W., Locke, B. Z, \& Goodwin, E K. (1993). The de facto U.S. mental and addictive disorders service system: Epidemiologic catchment area prospective 1-year prevalence rates of disorders and services. Archives of General Psychiatry, 50, 85-94.

Roberts, C. S. (1989). Conflicting professional values in social work and medicine. Health \& Social Work, 14, 211-218.

Sartorius, T. B., Ustun, J. A., Costa e Silva, J. A., Goldberg, D., Lecrubier, Y., Ormel, H., \& Von Korff, M. (1993). An international study of psychological problems in primary care (Preliminary Report from the WHO Collaborative Project on Psychological Problems in General Health Care). Geneva: World Health Organization.

Schlesinger, J. J., Mumford, E., Glass, G. V., Patrick, C., \& Sharfstein, S. S. (1983). Mental health treatment and medical care utilization in a fee-for-service system. American Journal of Public Health, 73, 422429. 
Gross, R., Rabinowitz, J., Feldman, D., Boerma, W. Primary health care physicians' treatment of psychosocial problems: implications for social work. Health \& Social Work: 1996, 21(2), 89-95

Schurman, R. A., Kramer, R D., \& Mitchell, J. B. (1985). The hidden mental health network: Treatment of mental illness by nonpsychiatrist physicians. Archives of General Psychiatry, 42, 8994.

Zayas, L. H., \& Dyche, L. A. (1992). Social workers training primary care physicians: Essential psychosocial principles. Social Work, 37, 247-252.

Zimmerman, M. A., \& Wienckowski, L. A. (1991). Revisiting health and mental health linkages: A policy whose time has come . . . again. J ournal of Public Health Policy, 12, 510-524.

Accepted October 3, 1995 